\title{
Osteoporosis - A Public Health Issue for Countries with Immigrant and Refugee Populations
}

\author{
George M.Weisz, MD, FRACS (ortho), BA, MA \\ A/ Professor, School of Humanities, University of New England, Armidale and Senior Lecturer, \\ University of New South Wales, Sydney
}

\begin{abstract}
There is growing evidence that in utero and early-life starvation programmes premature adult metabolic syndrome and bone demineralisation. In developing and low socioeconomic countries, there is significant risk of under nutrition during pregnancy. In refugees who were exposed to the risks of undernutrition in utero, risks may be further amplified by a rapid overfeeding in the newly adopted developed country. This narrative review outlines evidence for the health risks of under-nutrition during pregnancy earlylife starvation, and subsequent overfeeding and subsequent impact on bone health. Possible preventive measures are also outlined.
\end{abstract}

Keywords: Early life starvation, metabolic syndrome, immigrants, refugees.

\section{INTRODUCTION}

The year 2015 witnessed perhaps the greatest human migration ever seen from the underdeveloped, low socioeconomic countries of the Middle East, North Africa and Central and South America. These immigrants were heading to developed northern European countries and North America. Australia also has a history of welcoming immigrants and more recently Middle Eastern refugees fleeing war zones. However, the medical history of these migrant populations, including prenatal and early life exposures, may present unforeseen health problems requiring prophylactic measures.

It is likely that, if not addressed, the health problems caused by prenatal and early life under nutrition and starvation may result in medical conditions that place additional burden on the health system over the coming decades.

\section{HISTORICAL EVIDENCE}

Scientific findings regarding immediate effects of starvation on humans were published in 1941. These unique studies were conducted by 28 doctors incarcerated in the Warsaw ghetto during WWII. The research was performed over 17 months and documented in detail the effects of starvation on people who were given daily rations consisting of less than 800 calories and only 20-30 g protein. By July 1942, more than 40,000 people had died. [1,2].

The doctors observed multiple effects of starvation, particularly on the children, and most notably on their metabolic and endocrine functions. Their bone histology showed signs of "Hunger Osteopathy", including both architectural and matrix changes, namely osteoporosis and osteomalacia. Bone healing did not occur, making surgical fixation inexpedient.[1]

While the delayed effect of malnutrition on human development has been established for some time, rigorous scientific studies on the epidemiology of diseases associated with starvation, have only been conducted more recently.[3-5] The exact effect of early-life malnutrition on the development of adult diseases was discovered in the late 20th century, on populations exposed to hunger during their embryonic, foetal, neonatal or childhood periods, some 40-50 years earlier.[6-7]

\section{Early-Life Nutrition and Programming Adult Diseases}

During WWII, starvation was used by the German authorities as a weapon for submission or punishment, for example in Leningrad and the Netherlands. Starvation also occurred on the Channel Islands in 1944 when food supply was cut off as a result of the Allied invasion of Normandy. 


\section{George M.Weisz}

During the Leningrad siege the German army surrounded the city for over two years (September 1941 to January 1944) and the population of 2.9 million people, including 0.5 million children, were cut-off from food supplies. Approximately 830,000 people lost their lives.[8]. Forty years later, studies were conducted at the Karolinska Institute, Sweden, investigating the effects on children born to mothers who survived the siege with sustenance of only 300-800 calories per day during pregnancy. Findings showed a direct relationship between gestational deprivation and cardiovascular disease.[8,9]

In the Netherlands in November 1944, as a reprisal for interference with essential railway lines, a severe food embargo ('the Dutch embargo') was instituted by the occupying German forces upon the densely populated Western Netherlands. The food supplied per person was gradually reduced from an initial 1000 calories per day, down to 400 calories a day by April 1945. In total, 18,000 deaths were recorded as directly related to the famine. In a study conducted at Amsterdam University, the health records of those born during the siege found that they were small in stature, had an increased risk of metabolic disease and obesity, and had an increased mortality rate by age 50, compared to controls from the Eastern Netherlands. Changes were also identified in reproductive function, including early menopause, and increased incidence of breast and colon malignancy.[10-12]

The significant difference between the Leningrad siege and the Dutch embargo was that after liberation, the 'catch up' feeding in the Dutch cohort was rapid and sudden, whilst in Leningrad, the economic recovery was slow and occurred over a period of several years.

The famine resulting from the German occupation of the Channel Islands (1940-1945) involved the entire population of 60,000 people as well as the occupiers who had been left behind as the invasion of Normandy in 1944 by-passed the islands. The food supply was cut off, and by the end of 1944/early 1945 the shortage had become critical.[13-14] It was found that children exposed to undernutrition had increased risk of cardiovascular morbidity, delayed menarche, and a trend towards increased risk of breast cancer compared to the matched controls evacuated to England.

Further studies using birth registry data on a large peacetime population of England and Wales added to evidence for the effect of early-life nutrition on the development of diseases in adults.[5-18]

This historical data led to the well-known 'Barker Hypothesis' which proposes that there is adjustment in utero via a "re-printing" or "programming" mechanism. In 1992 further hypotheses that metabolic syndrome may result from in utero starvation and developmental plasticity were published.[4,5]

In more recent studies, a predisposition to the development of metabolic disease in the Nauru population, was observed once the island became commercially enriched. The mineral boom in the country led to "westernisation" of diet, and the Micronesian islanders were at increased risk of obesity and diabetes, and was trans-generational.[6]

Similarly, a Swedish study on the Biafran population, approximately 40 years after exposure to starvation, also observed increased occurrence of metabolic syndrome.[7]Most strikingly, however, was the fact that the theory that exposure to early life starvation increasing the risk of metabolic syndrome has been reproduced experimentally in animal models in numerous experiments.

However, none of the above initial studies dealt with bone mineral metabolism. The fetal programming of musculo-skeletal pathology (adipose tissue, sarcopaenia, osteopaenia) and effect on health in later life was developed somewhat later.

\section{Intrauterine Nutrition as a Programmer of Adult Osteoporosis}

There is a plethora of publications that support the theory that early life malnutrition and later metabolic changes may be influential in programming increased risk for adult osteoporosis.

Cooper et al.(2000) described the pathogenesis of osteoporosis and attributed a role to intrauterine programming. This was a confirmation of an earlier analysis of growth in infancy and bone mass in adult life. In 2004, osteoporosis was considered to be of developmental origin, with significant impact on the risk of future fracture.[18-25]. By 2012, the epigenetic influence on the developmental origin of osteoporosis was established.[26] The possible generational transfer of the metabolic insult suffered by one generation is also of possible relevance. 


\section{Health Surveillance for Immigrants from Low Socioeconomic Countries and Refugees}

Due to early life events and exposure to hardship, it is vital that countries accepting immigrants and refugees are prepared for the likely increased health risks. In particular, it is important that funds and resources are directed towards prevention of osteoporosis, including early diagnosis, immediate treatment and reduction of fracture and secondary fracture risk.[26-30] The cost-savings by taking a preventative approach are likely to be considerable.

The risks are three-fold: The primary risk is starvation in utero (whether total, partial or selective). The risks are also trimester sensitive, for example, protein and glucose deficiency may influence brain development in the first trimester; of cortisol and growth hormone deficiency may influence bone and internal organ development during the second trimester and limb and kidney development during the third trimester.[3,31].

Offering additional health screening of immigrant populations for markers such as Glycated Haemoglobin (HbA1c), lipids (triglycerides, cholesterol with fractions, and the screening for minerals (e.g., calcium, magnesium, phosphates, vitamin D), may be required. A minor cost, (totalling some AUS=32), would allow identification and instigation of preventative measures for those at risk of diabetes, of obesity, atherogenesis and bone demineralisation (our preferred term Low Nutrition osteopathy). Vitamin K deficiency may also lead to paradoxical mineralisation, namely epiphyseal and arterial wall calcifications, and premature osteoporosis in adults.

The secondary risk is sudden compensatory hyper alimentation, or so called "catch-up overfeeding", leading to adolescent obesity, early adult glucose and lipid metabolic disturbance, and full-blown adult metabolic syndrome, including osteoporosis (high nutrition osteopathy). Studies have shown that catch-up bone metabolism is only partially achieved and may even exaggerate osteopathy by partial mineralisation. $[25,26]$.

An osteoporosis prevention program will require a significant educational effort; similar measures were taken in Austria following a nationwide review of diabetes in the population born during starvation periods. [3, 6, 7, 31]

The third risk is of the surprising findings (even if at times with limited statistical significance), on the frequency of malignancy in individuals starved during their intrauterine or perinatal life, compared to the rest of the population. $[11,12,14,32]$

\section{CONCLUSION}

Osteoporosis, just as with other metabolic disorders, was found to be programmed by conditions of early life, mostly intrauterine starvation or partial nutritional deprivation. It appeared in both genders, more prominently in females, with significant risk of increased fracture incidence. Nutritional science has advanced with major steps in the last quarter of a century, demonstrating two separate aspects of bone growth and presenting two separate but inter-dependent metabolic bone syndromes, both related to maternal starvation during pregnancy. Some children do not achieve catch-up growth, remain short into adulthood, with increased coronary and cerebral artery disease and osteoporosis.[33].

\section{REFERENCES}

[1] Winnick MD. Hunger Disease: Studies by the Jewish Physicians in the Warsaw Ghetto. New York: John Wiley \& Sons; 1979: pg.216.

[2] Roland, C G: Courgeunder Siege, Starvation, Disease and Death in Ghetto Warsaw. Oxford Uni.Press. 1992.

[3] Thurner S, Klimek P, Szell M, et al : Quantification of excess risk for diabetes for those born in times of Hunger, in an entire population of a nation, across a century. Proc. Natl. Acad. Sci. USA. 2013;110: (12):4703-7.

[4] Glucksman PD, Hanson MA, Spencer HG, Bateson P: Environmental influences during development and their consequences: Proc. Roy. Society .2005, 272:671-7.

[5] Ben-Shlomo Y, Kuh D:A life course approach to chronic disease epidemiology: Int. J. Epidemiol. 2002,31:285-93.

[6] Zimmet P, Taft P. et al.: The high prevalence of diabetes mellitus on a central pacific island. Diabetologia, 1977; 13:111-5.

[7] Hult M, Tornhammar P, et al.: Hypertension, Diabetes and Overweight: looming legacies of Biafran Famine. POLOS October 2010 DOI: 10.1371 
[8] Koupil I, Shestov DB, Sparén P, et al: Blood pressure, hypertension and mortality from circulatory disease in men and women who survived the siege of Leningrad. European Journal of Epidemiology; 2007: 22, 223-234.

[9] Rotar O, Moguchaia E, et al: Seventy years after siege of Leningrad. J. of Hypertension , 2015; 33(9):1772-9.

[10] Roseboom T. de Rooij S, Painter R:The Dutch famine and its long-term. consequences for adult health. Early Human Development. 2006: 82, 485-491.

[11] Dirx MJM, van den Brandt PA, Goldbohm RA, Lumey LH: Energy restriction early in life and colon carcinoma risk. Cancer:2003; 97,46-55.

[12] Elias SG, Peeters PHM, Grobbee DE, van Noord PAH: Breast cancer risk after caloric restriction during the 1944-1945 Dutch famine. Journal of the National Cancer Institute.2004; 96, 539-546.

[13] Head RF, Gilthorpe MS, Byrom A, Ellison GTH : Cardiovascular disease in a cohort exposed to the 1940-45 Channel Islands occupation.BMC Public Health.2008; 8, 303-307.

[14] Fentiman IS, Allen DS, Ellison GTH. The impact of the occupation of Guernsey 1940- 1945 on breast cancer risk. Int J. ClinPract.2007; 61:937-43.

[15] Lucas A: Programming by early nutrition in man. In 'The childhood environment and adult disease (Ciba Foundation Symposium 1991).

[16] Barker DJ, Winter PD, Osmond C, Margetts B, Simmonds SJ (1992): Weight in infancy and death from ischemic heart disease. In 'Fetal and infant origins of adult disease'. (Ed.DJBarker) pp. 141-148.n)

[17] Barker DJP. Fetal origins of coronary heart disease. BMJ 1995; 311:171-4.

[18] Sayer AA, Cooper C: Fetal programming of body composition and musculoskeletal development. Early Human Development .2005; 81, 735-744.

[19] Cole ZA, Gale CR, Javaid MK, Robinson SM, Law C, Boucher BJ, Crozier SR, Godfrey KM, Dennison EM, Cooper C: Maternal dietary patterns during pregnancy and childhood bone mass: a longitudinal study. Journal of Bone and Mineral Research.2009: 24, 663-668.

[20] Gale CR, Martyn CN, Kellingray S, Eastell R, Cooper C : Intrauterine programming of adult body composition. The Journal of Clinical Endocrinology and Metabolism .2001; 86: 267-272.

[21] Cooper C, Walker-Bone K, Arden N: Novel insights into the pathogenesis of osteoporosis: the role of intrauterine programming. Rheumatology 2000: 39, 1312-1315.

[22] Cooper C. Javaid M K, Taylor P, Walker-Bone K, Dennison E, Arden N: The foetal origins of osteoporotic fracture. Calcified Tissue International 2002:70, 391-394.

[23] Cooper C, Javaid K, Westlake S, Harvey N, Dennison E: Developmental origins of osteoporotic fracture: the role of maternal Vitamin D insufficiency. The Journal of Nutrition.2005: 135, 2728S-2734S.

[24] Dennison EM, Arden NK, Keen RW, Syddall H, Day INM, Spector TD, Cooper C : Birth weight, vitamin D receptor genotype and the programming of osteoporosis. Paediatric and Perinatal Epidemiology .2001: 15, 211-219.

[25] McCance26. McCance RA: Food, growths and time .The Lancet 1962;72(58)671-83.

[26] Gat-Yablonski G, Philip M: Nutritional-Induced catch up growth. Nutrients 2015. 7(1):517551.doi:10.3390/nu7010517.

[27] Weisz GM, Albury WF.: Osteoporosis in survivors of early life starvation. Aust. J. Prim. Health. 2013;19:3-6.

[28] Weisz.GM. Albury WR. : Hungry "In Utero" programming osteoporosis. Rambam Maimonides Medical Journal. 2014; 5(1), ID 0004.

[29] Kimber C, Grimmer-Somers K: A novel primary care clinical prediction rule for early detection of osteoporosis. Aust.J.of Primary Health. 2011: 17, 175-180.

[30] Paratz ED, Katz B: Ageing Holocaust survivors in Australia. The Medical Journal of Australia.2011: 194(4), 194-197.

[31] Kueper J, Beyth S, Lebergall M, Kaplan L, Schoeder JE: Evidence for the Adverse Effect of Starvation on Bone quality: a Review. Int.J.Endocrin: 2015, Article ID $628740 .$.

[32] Keinan-Boker L, Vin-Raviv N, et.al: Cancer Incidence in Jewish Survivors of WWII. J. Nat.Cancer Inst. 2009; 101(21): 1489-1500.

[33] Jancevska A, Tasic V. et al: Children born small for gestational age. Prilozi 2012, 33(2):47-58. 